\title{
الأبعاد النفسية لرسوم الأطفال ودور الفن في بناء شخصية الطفل"
}

\author{
إعداد \\ آمنة عبد|لسلام جاد الشاذلمسل \\ (باحث ماجستير) \\ تحت إثراف
ه / مروة السيد عبد|لرؤف
مدرس التصميم بقسم التربية الفنية
كلية التربية النوعية - جامعة المنصورة
أ.م.د / حناض محمد الشربينحس.
أستاذ التصميم المساعد بقسم التربية الفنية
كلية التربية النوعية - جامعة المنصورة

مجلة بحوث التربية النوعية ـ جامعة المنصورة

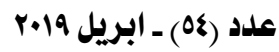




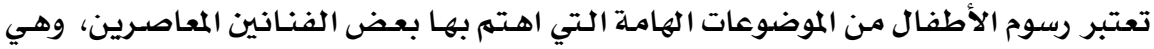

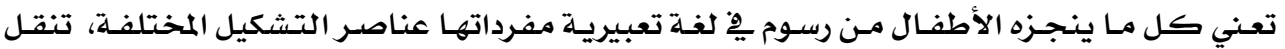

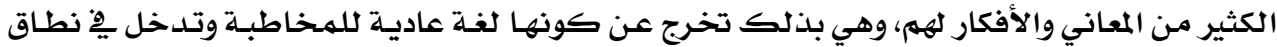

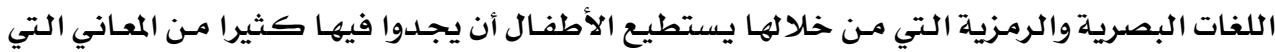

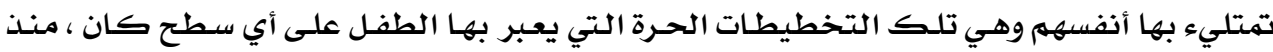

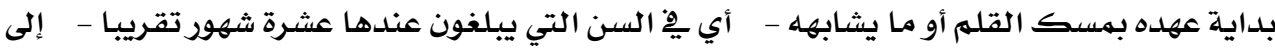

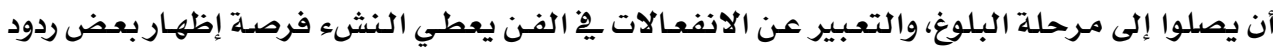

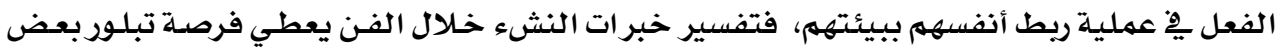

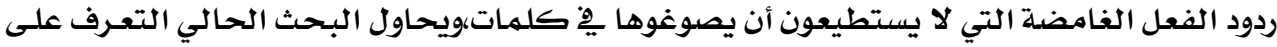

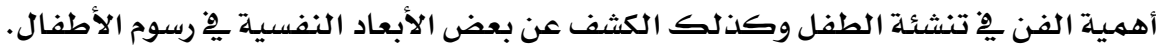

همبد

الفن صورة من صور الحياة ِِْ أرقى حالاتها بل إن الحياة ِِّ أحسن تكاملها وشمولها لا

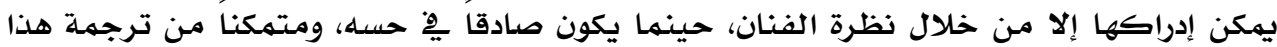

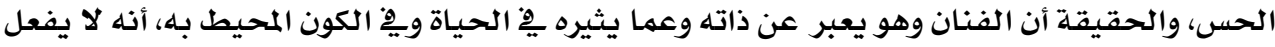

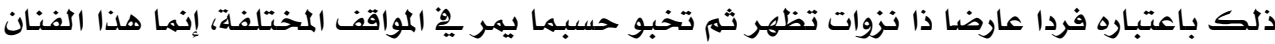

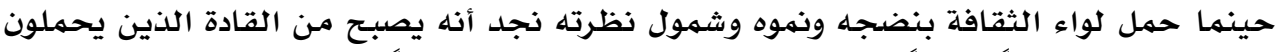

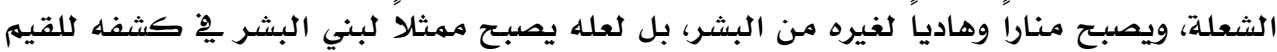

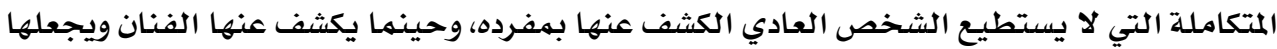

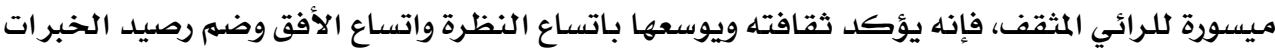

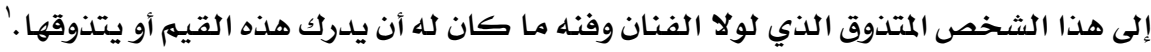

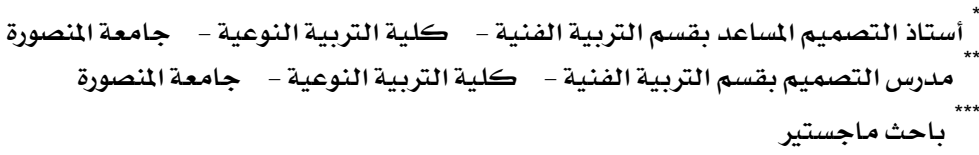
1 محمود البسيوني وآخرون: "طرق تدريس التربية الفنية للصف الرابع لدور المعلمـين والمعلمـات لجميع الشعب"، القاهرة،

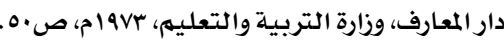


والفن مهما اختلفت أساليبه أو طرائقه ما هو إلا وسيلة مـن وسائل التعبير عن النفس بكل

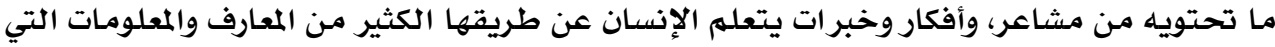

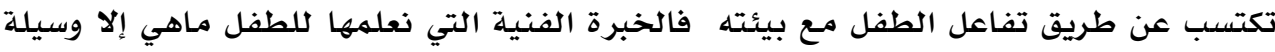

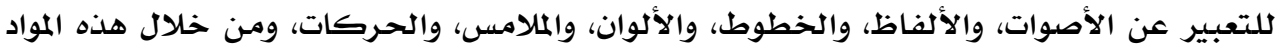

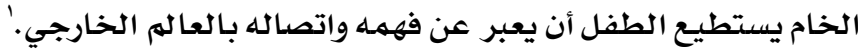

ويذخر التراث السيكولوجي اليوم ببحوث متتنوعة ووفيرة عن علاقة رسوم الأطفال بالعوامل

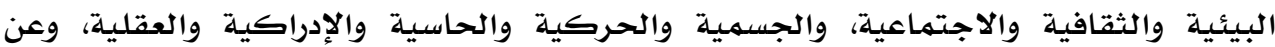
استخدامـاتها كوسيلة لقياس الذكاء، ولسبر أغوار الشخصية والكثف واهيه عن خباياها، وكأداة للعلاج

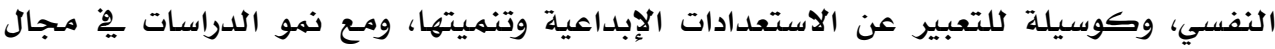

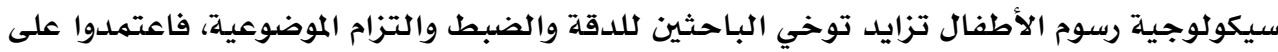

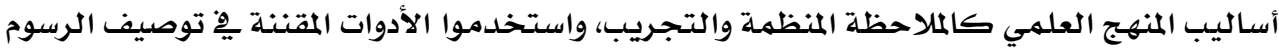

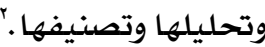

فالطفل يلعب بجسده كها يلعب بخياله وفكره، يمرح هنا وهناك يكتشف لكي ينهي

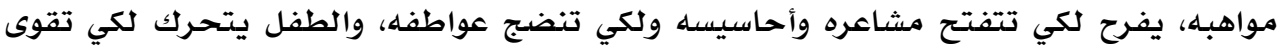

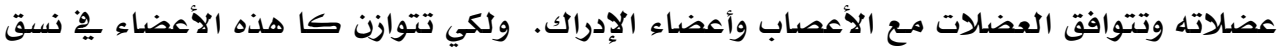

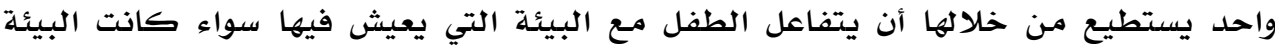

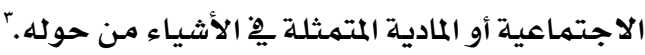
إن التعبير عن الانفعالات ِِّ الفن يعطي النشء فرصة إظهار بعض ردود الفعل ِِّ عملية ريط أنفسهم ببيئتهم، فتفسير خبر ات النشء خلاءل الفن يعطي فرصدة تبلور بعض ردود الفعل

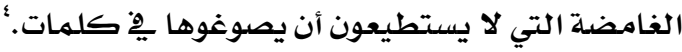

مشكلة البحث

مما سبق يتضح أهمية دراسـة رسوم الأطفال وضرورة الاهتمام بها بشكل أوسع بها لها من أهمية كبيرة ِِّ حياة الطفل ونشأته. يحاول البحث الحالي دراسة دور الفن ِِّ بناء شخصية الطفل وتوضيح بعض الأبعاد النفسية ِِِ رسوم الأطفال.

ومن خلال العرض السابق يمكن استخلاص مشكلة البحث يِّ التساؤل الأتي :

هل هناك دور للفن بِ بناء شخصية الطفل من خلال رسوم الأطفال؟

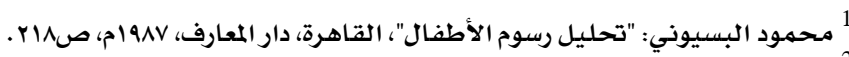

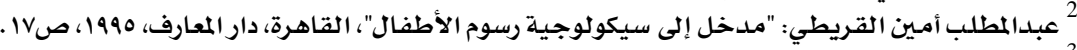

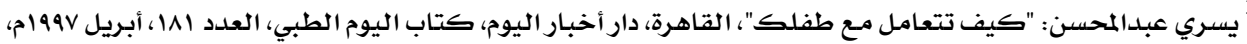

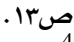
مححمود البسيوني وآخرون: "طرق تدريس التربية الفنية للصف الرابع لدور المعلمين والمعلمات"، مرجع سابق، ص9. 


\title{
أهد|ف البمث
}

\author{
- الكثف عن أهمية الفن ِِّ حياة الطفل. \\ - الكثف عن بعض الأبعاد النفسية ِِِ رسوم الأطفال. \\ أهمية البحث البمث عن
}

- التعرف على أهمية الفن بِّ تنشئة الطفل.

- الكشف عن علاقة البيئة والفن ونفسية الطفل.

فروض البمث

- هنالك علاقة إيجابية بين الفن والبعد النفسي ِِّ رسوم الأطفال.

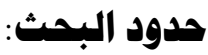

- مراسة دور الفن ِِّ بناء شخصية الطفل.

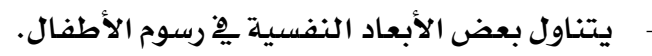

هنهمج البمث

يستند البحث الحالي على المنهج الوصفي القائم على التحليل.

همطات البمث

الفن : Art

تعرف الموسوعة البريطانية الفن على أنه التعبير عن الأفكار الجمالية، عن طريق توظيف

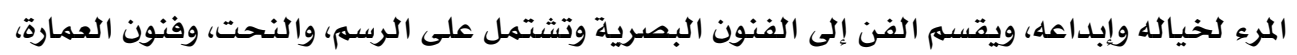

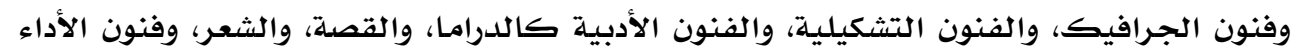
كالموسيقى، والمسرح، والرقصن والفنون التشكئ

\section{Children's drawings رسوم الأطفال}

هي تلك التخطيطات الحرة التي يعبر بها الطفل على أي سطح كان ، منذ بداية عهلده

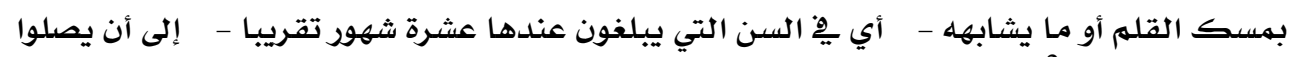
إلى مرحلة البلوغ.

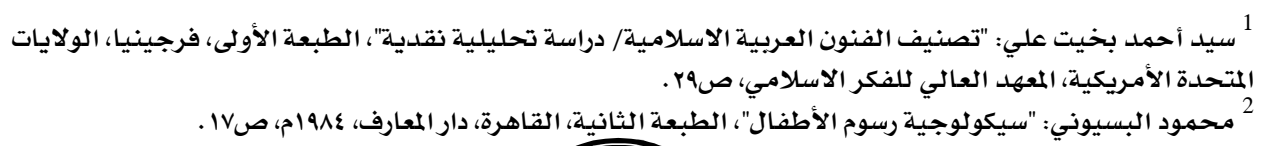




\section{راسوم الأطفال}

تعتبر رسوم الأطفال من الموضوعات الهامـة التي اهتم بها بعض الفنانين المعاصرين، وهي

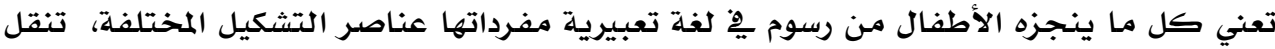

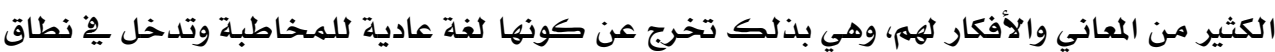

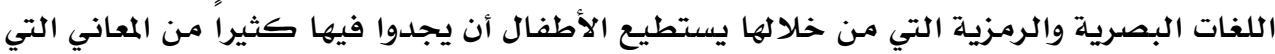

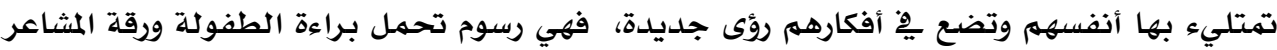

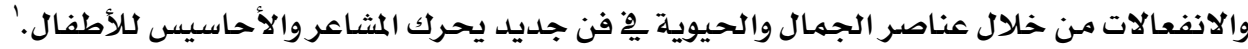

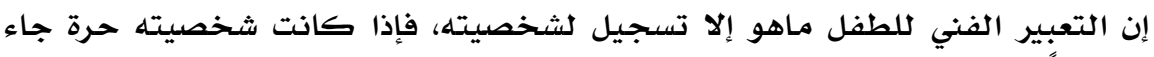

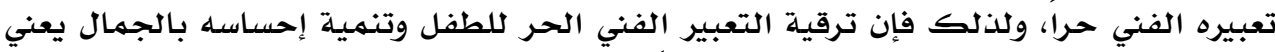

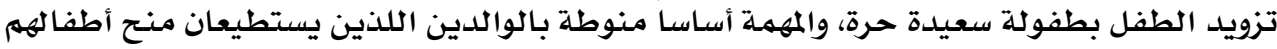
كل الحب والجمال، وبالطبع عليهما تفهم حاجات الطفل حسب نموه وسنـه من خلال تجرئ تجريتهما

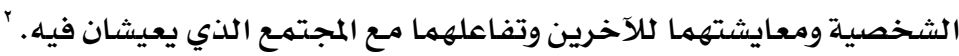
معني الفز بالنسبة للطفل

إن كل شيء ِِْ نظامنا التربوي يتجه نحو التعلهم الذي يعني ِِّ كثير من الأحوال

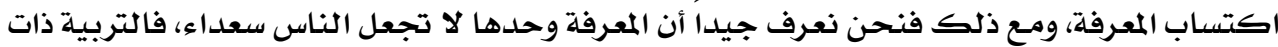

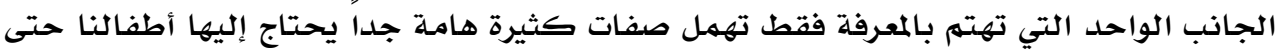

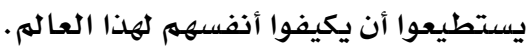

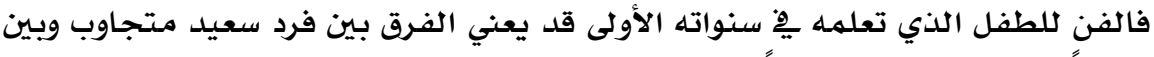

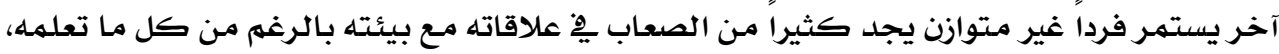

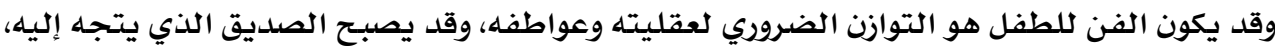

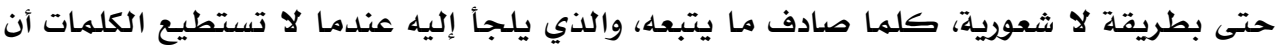
تسعفه.

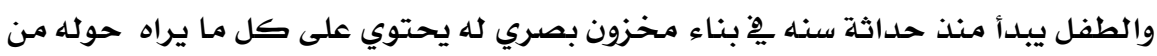

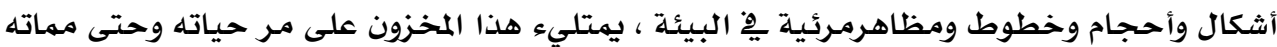

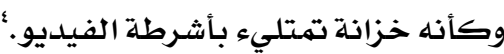

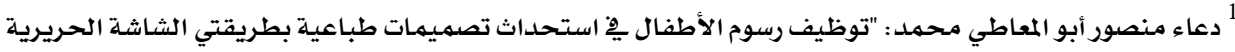

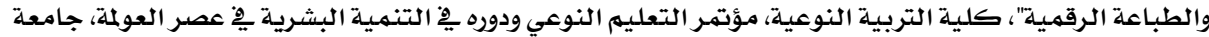

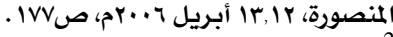

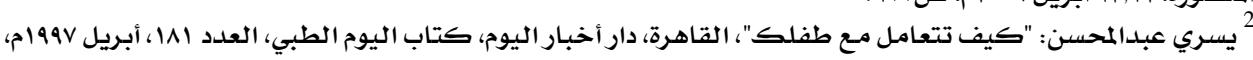

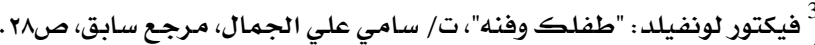

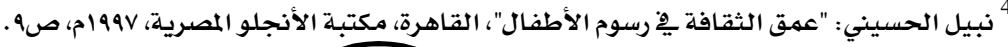


إنه لا حاجة إلى أن نصحس أي نسبة يِّ رسوم الأطفال، ويجب أن نهتم بالمحافظة على حرية

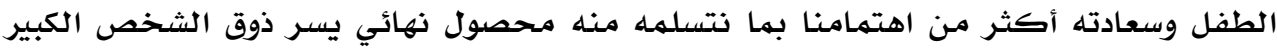

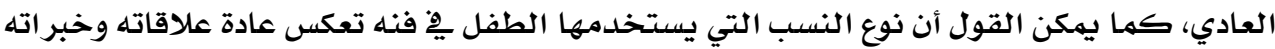

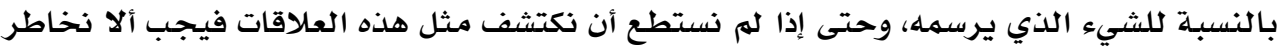

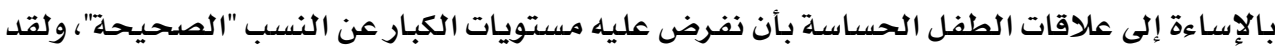

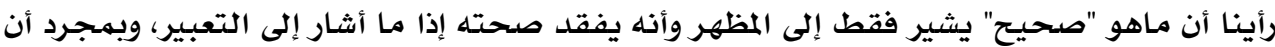

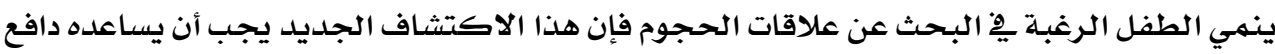

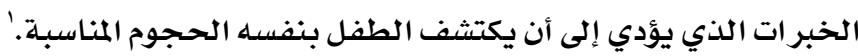

البعد النفسي لرسوم الأطفال

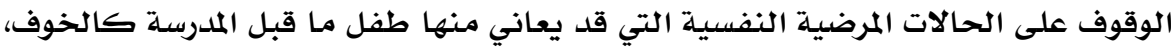

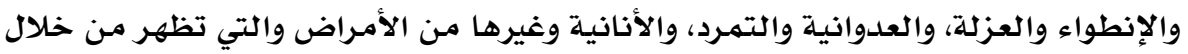

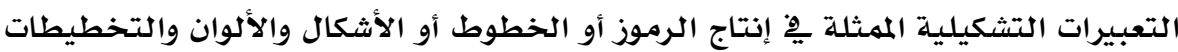

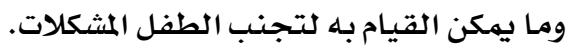

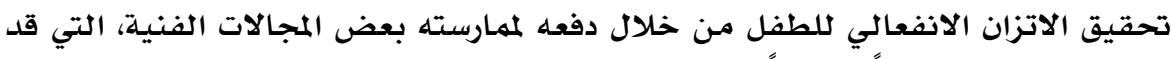

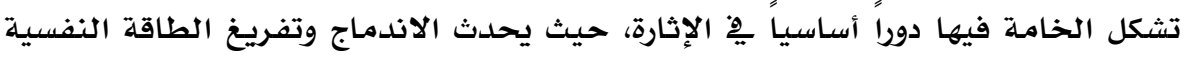
والجسمانية من خلال الحركة والمثاركة. محاولة إيجابية لدمج الطفل مـع أقرانه يِ بيئة للعمل والمنافسـة التلقائية. التبصر بخصائص الأطفال المبدعين ِِّ مرحلة مبكرة، وبحث سبل تنميتهم من خلال الدافعية يِ الممارسة شبه الفنية، وتحليل أنظمة السلوكيات الفنية التلقائية أو المقصودة.

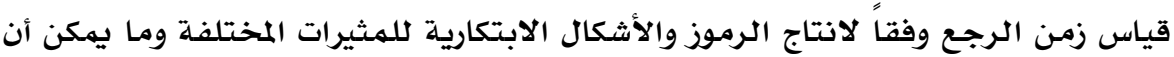
تحدثه من دافعية للطفل يِّ الممارسات الفنية. رؤية مدى قدرة الطفل العقلية، من خلال إيجاد علاقة بين ذكاء الطفل والقدرة على رسم ملهم التفاصيل. إن احتياجات الطفل كثيرة وفهم هذه الاحتياجات يحتاج إلى وعي وإدراك جيد من

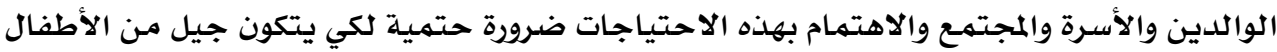

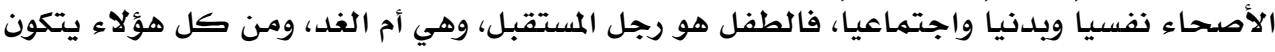

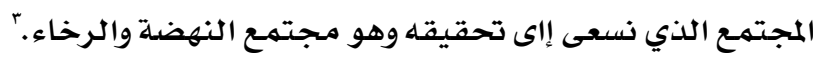

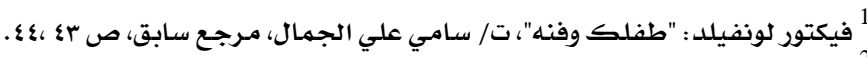

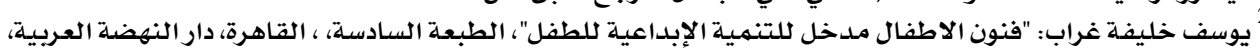

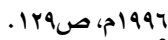
3يسري عبدالمحسن: "كيف تتعامل مـع طفلك"، مـرجـع سـابق، ص10 . 
وتعد التربية الفنية من المواد التربوية القليلة والنادرة المتوفرة ِِْ مناهجنا التعليمية

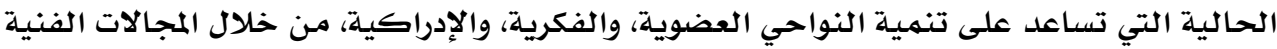

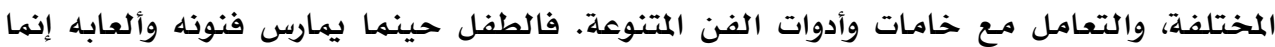

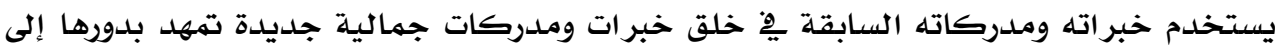

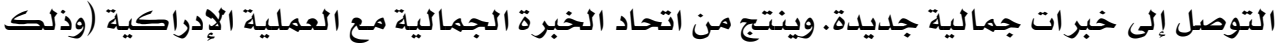

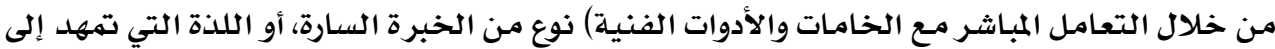

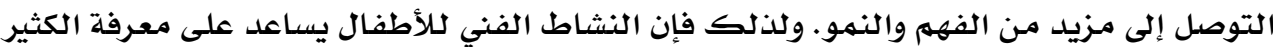

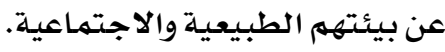

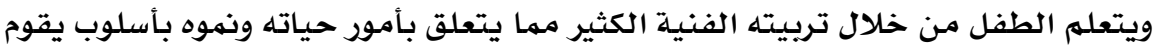

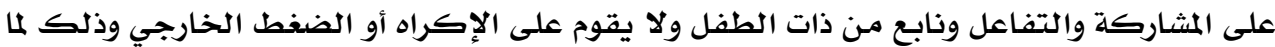

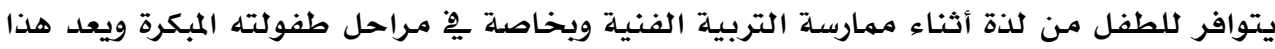

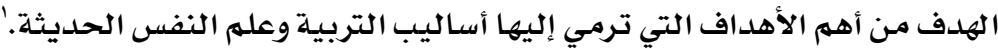

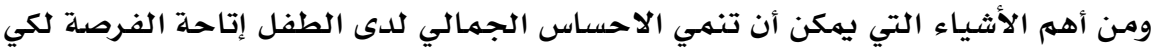

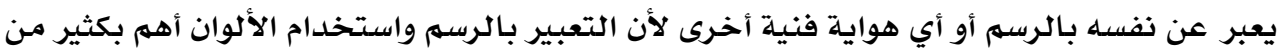

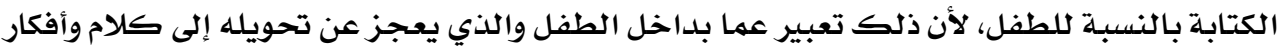

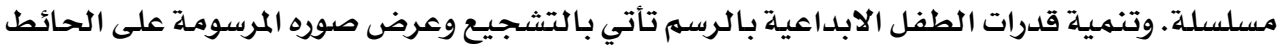

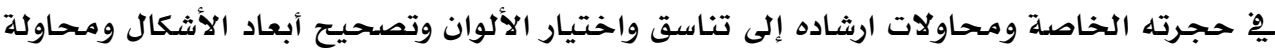

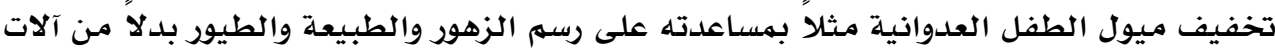

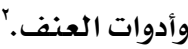

دور التربية الفنية في بناء شخصية الطفل:

$$
\text { - - تنميلة السلوك الابتكاري. }
$$

- تنمية الحساسية الفنية والتذوق الفني.

$$
\text { - - تمو القدرات العقلية. }
$$

تكامل شخصية الطفل وتأكيد ذاته.

- - التنفيس عن بعض الانفعالات.

- مالاهتمام بالفروق الفردية.

- تلدريب الحواس وتنميتها.

- - لغة تساعد على الاتصال.

- اللعب بالخامات المختلفة.

عبلة حنفي عثمان: "فنون أطفالنا"، الطبعة الثانية، مرجـع سابق، صوبـ.

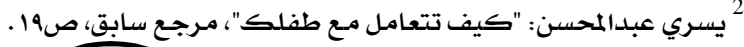




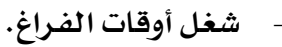

$$
\begin{aligned}
& \text { - تنهية الاتجـاه النقدي عند الأطفال. } \\
& \text { تنهية الناحية الثقافية. } \\
& \text { - مالكشف عن المواهب الفنية. }
\end{aligned}
$$

والطفل يستشعر الجمال ويبـحث عن الهدوء وراحة البال وتستقر نفسيته وترتاح أعصابه مـع جمال الطبيعة وصفاء الجو فهو أيضا يحتاج إلى الخضرة والمياه والشمس والهواء الطلق مثلهما يحتاج الكبير وهو يتذوق الجمال ويتعايث معهد ويتشكل بـه، وكلها توافر لله هذا المناخ كان أكثر سعادة، واستطاع أن يلعب ويأكل ويفرح وينهمو بصورة طبيعية، وعلى العكس فهو دائم الحزن والتوتر مـع الضوضـاء ودائم القلق والخوف مـع تلوث الجو وفسـاد الهواء. وتشير الأسـاليب المعرفية إلى الاختلافات بين الأفراد يِ أساليب الإدراك والتذكر والتخيل والتفكير، كما تهثل الفروق فيما بينهم من حيث طرق الفهم والحفظ والتحويل واستخدام المعلومات، وقد حظيت هذه الأساليب باهتهـام الباحثين وكشف دراساتهم عن أن لكل فرد أسلوبـه

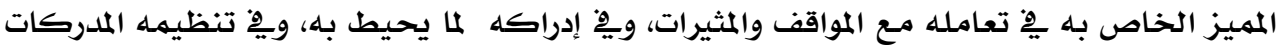
والاحتفاظ بها يه ذاكرته، كما كشفت عن تنوع تلك الأساليب الإدراكية المعرفية، ومن بينها أساليب الاعتماد - الاستقلال عن المجال الإدراكي، والمرنة - التصلب، والتفتح - الانغلاق، والاندفاع

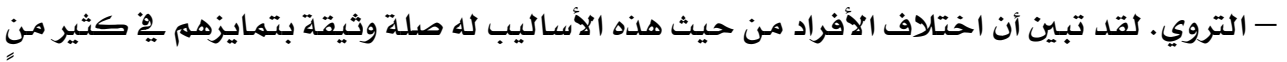
الأبعاد النفسية، ويبـدو بصفة خاصدة أن أسـاليب الاستقلال والمرونة والتفتح والتروي أكثر ارتبـاطا

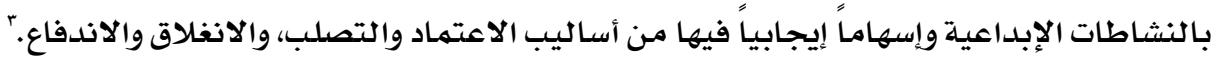
وكل هذه الخصائص لعب عليها كبار الفنانين عبر العصور وتفاوتوا يخ مستويات

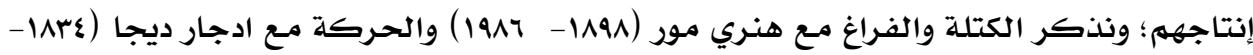

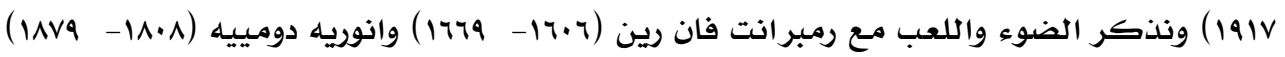

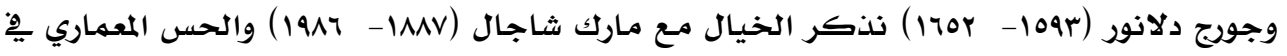

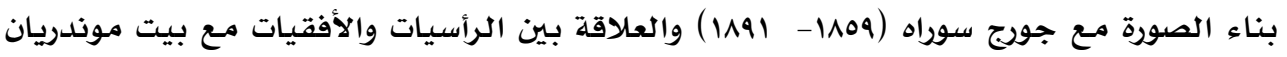

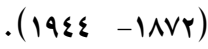

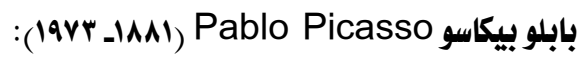

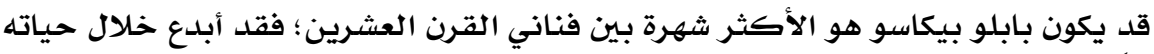

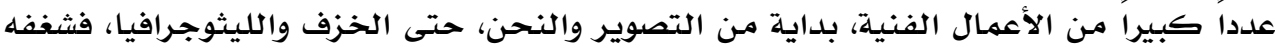


بالتجريب وشجاعته ِِّ استخدام أساليب واتجاهات مختلفة أنتجا إبداعات أحدثت أثراً كبيراً ِِّ.

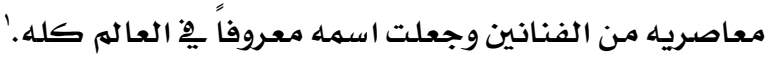

لقد احتضن بابلو بيكاسو كثيراً من الأساليب الرمزيـة التي يعتمد عليها الطفل مِّف تعبيره التشكيلي، وفضل ذلك عن صياغة الأثكال بصرياً.

وهو أسباني المولد، استوطن باريس، كان أبوه معلم رسم (جوزي رويز بلاسكو) أعطى ابنه

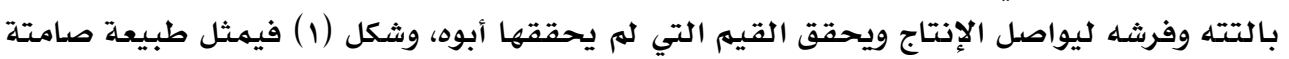

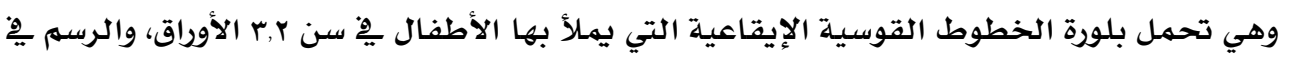

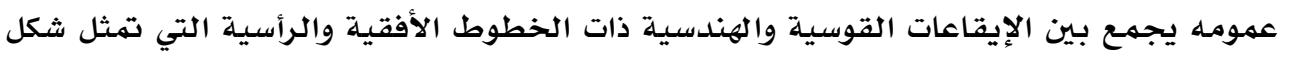

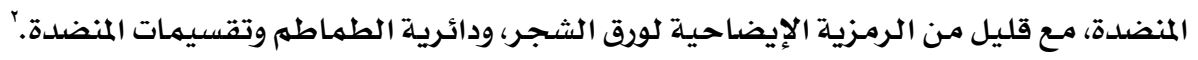

من أقواله: "كل طفل هو فنان، المشكلة هي أنه كيف يحافظ على ذلك عندما يكبر".

"عليك أن تعلم طفلك أنه معجزة وفريد من نوعه، وأنه يِ كل السنين التي مرت لا يوجد

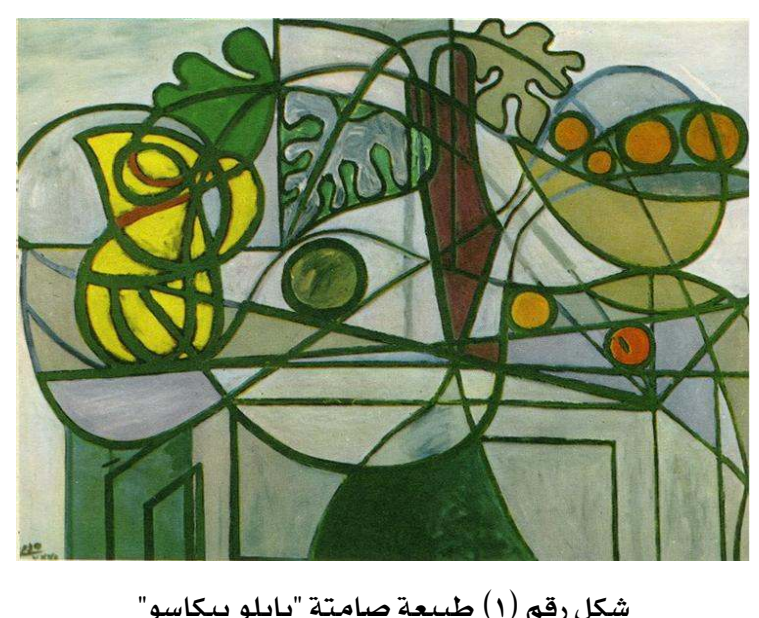

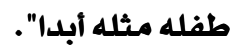

شكل رقم (1) طبيعة صامتة "بابلو بيكاسو"

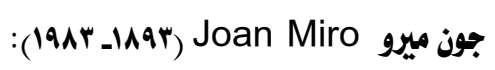

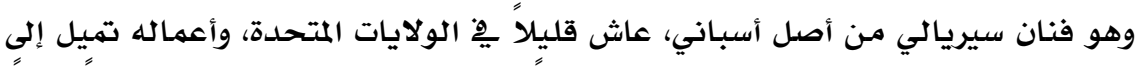

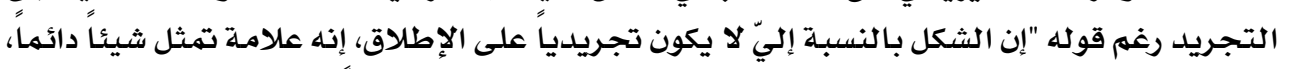

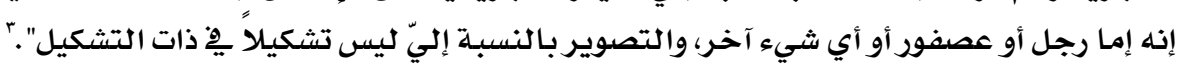

1 كيت سكاريوروف: "فنانون عالميون - بابلو بيكاسو"، جr، ت/حازم طه حسين، القاهرة، الهيئة المصرية العامـة للكتاب،

.

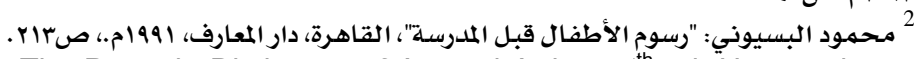

${ }^{1}$ Peter and Linda Murray, The Penguin Dictionary of Art and Artists, $5^{\text {th }}$ ed, Harmondsworth, Middlesex, England: Penguin Books, 1984, P274. 
فخلق رموزه وجعلها تقترب من الأشكال التي تسبق فترة الرمزية عند الأطفال، وبلور

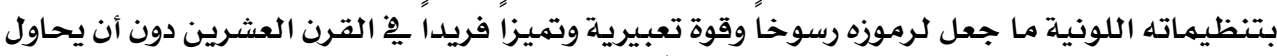

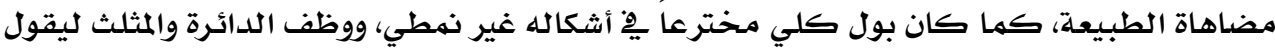

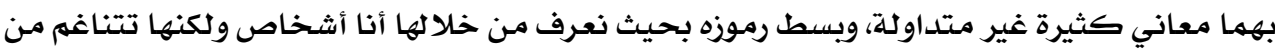
غير نسب محفوظة لتقول الكثير.'

والصورة (r) دونا وسمكة موسى، تبين الرمزية المميزة التي يعتنقها ميرو، فالعيون الدائرية

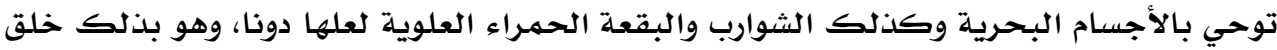

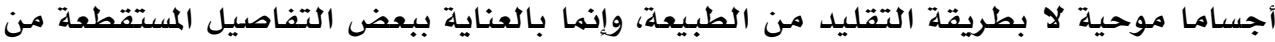

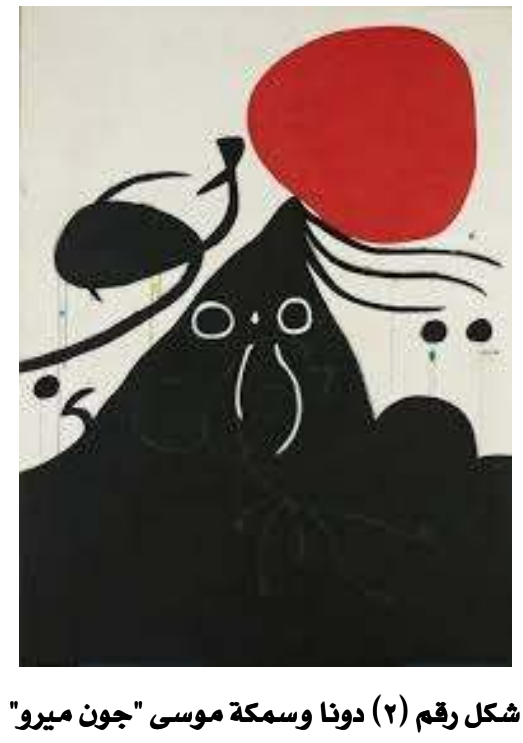

الطبيعة.

شكل رقم (Y) دونا وسمكة موسى "جون ميرو"

المراجع:

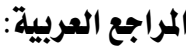

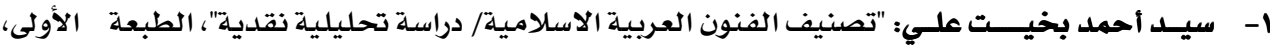

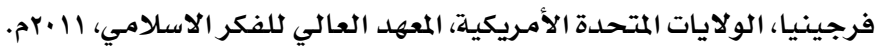

r - عبدالمطلب أميـن القريطي: "مدخل إلى سيكولوجية رسوم الأطفال"، القاهرة، دار المعارف، 1990 م.

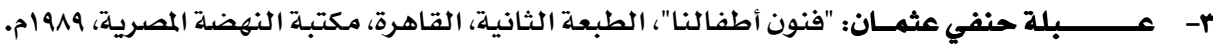
ع- محمود البسيوني وآخرون: "طرق تدريس التربية الفنية للصف الرابع لدور المعلمين والمعلمات لجميع

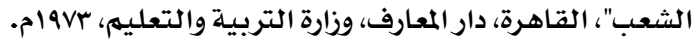

محمود البسيوني: "رسوم أطفال قبل المدرسة"، مرجع سابق، صلr.r. . 


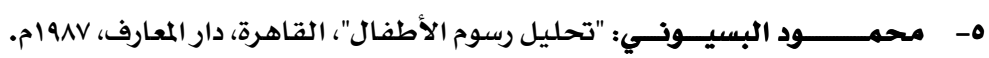

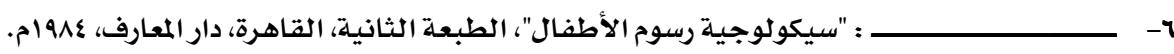

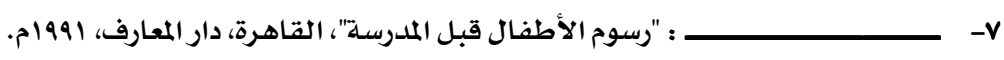

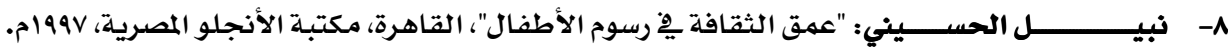

هـ يسـري عبدالمحســـــــ "كيف تتعامل مـع طفلك"، القاهرة، دار أخبـار اليوم، كتاب اليوم الطبي،

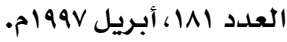

• ا- يوسف خليفة غراب: "فنون الاطفال مدخل للتنمية الإبداعية للطفل"، الطبعة السـادسة، ، القاهرة، دار

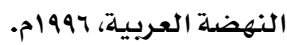

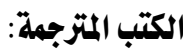

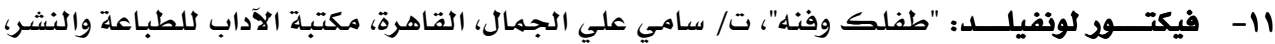
.1971

rا - كيـت سـاريوروف: "فنانون عالميون - بابلو بيكاسو"، جr، ت/حازم طه حسـين، القاهرة، الهيئة المصرية العامهة للكتاب، با • بم.

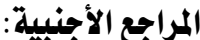

13- Peter and Linda Murray, The Penguin Dictionary of Art and Artists, $5^{\text {th }}$ ed, Harmond-sworth, Middlesex, England: Penguin Books, 1984. 